\title{
Independent Information of Nonspecific Biomarkers in Exhaled Breath Condensate
}

\author{
Holger Dressel ${ }^{\mathrm{a}} \quad$ Florian Müller $^{\mathrm{a}} \quad$ Rainald Fischer $^{\mathrm{b}} \quad$ Horst Römmelt $^{\mathrm{a}}$ \\ Jens M. Hohlfeld ${ }^{d}$ Jürgen Behr ${ }^{c}$ Rudolf M. Huber ${ }^{b}$ Dennis Nowak ${ }^{a}$ \\ Rudolf A. Jörres ${ }^{a}$ \\ ${ }^{a}$ Institute and Outpatient Clinic for Occupational, Social and Environmental Medicine, ${ }^{b}$ Department of \\ Pneumology, Medizinische Klinik Innenstadt, and ${ }^{\mathrm{C}}$ Department of Internal Medicine I, Division of Respiratory \\ Diseases, Klinikum Grosshadern, Ludwig-Maximilians-University, Munich, and ${ }^{\mathrm{I}}$ Fraunhofer Institute for \\ Toxicology and Experimental Medicine, Hannover, Germany
}

\section{Key Words}

Exhaled breath condensate $\cdot$ Conductivity $\cdot$ Ammonia $\cdot$ $\mathrm{pH} \cdot$ Nitrite $\cdot$ Nitrate $\cdot$ Exhaled nitric oxide $\cdot$ Factor analysis

\begin{abstract}
Background: Exhaled breath condensate (EBC) has been used for diagnosing and monitoring respiratory disorders. For clinical purposes the assessment of easy-to-obtain nonspecific markers seems particularly interesting. Objectives: As these measures are related to each other, our objective was to extract the independent information in global EBC markers across a range of respiratory disorders. Methods: EBC was collected from patients with asthma $(n=18)$, chronic obstructive pulmonary disease $(n=17)$, and cystic fibrosis $(n=46)$, as well as from lung transplant (LTX) recipients $(n=$ 14) and healthy controls $(n=26)$. Samples were assessed for electrical conductivity, ammonia, $\mathrm{pH}$, and nitrite/nitrate. $\mathrm{pH}$ was measured after both deaeration with argon and $\mathrm{CO}_{2}$ standardization. Additionally, the fraction of exhaled nitric oxide $\left(\mathrm{FE}_{\mathrm{NO}}\right)$ was assessed. Factor analysis was applied to
\end{abstract}

identify major factors concerning these measures. Results: Three independent factors were detected; the first comprised conductivity, ammonia, and $\mathrm{pH}$, especially when standardized using $\mathrm{CO}_{2}$, the second nitrite/nitrate, and the third $\mathrm{FE}_{\mathrm{NO}}$. Conductivity and ammonia were highly correlated $(r=$ 0.968; $p<0.001$ ). $\mathrm{FE}_{\mathrm{NO}}$ provided independent information mainly in asthma. The nonspecific EBC markers showed considerable overlap between patient groups and healthy subjects. However, conductivity, ammonia, pH standardized for $\mathrm{CO}_{2}$ and nitrite/nitrate were increased in LTX recipients compared to healthy controls ( $p<0.05$ each). Conclusions: $A$ panel of nonspecific easy-to-obtain exhaled breath markers could be reduced to 3 independent factors. The information content of conductivity, ammonia, and $\mathrm{pH}$ after $\mathrm{CO}_{2}$ equilibration appeared to be similar, while $\mathrm{FE}_{\mathrm{NO}}$ was independent. The increased levels of these biomarkers in LTX might indicate a potential for their use in these patients.

Copyright ๑ 2010 S. Karger AG, Basel

The data represent part of the medical doctoral thesis of F. Müller.

\section{KARGER}

Fax +4161306 1234 E-Mail karger@karger.ch www.karger.com
(C) 2010 S. Karger AG, Basel

0025-7931/10/0805-0401\$26.00/0

Accessible online at:

www.karger.com/res
Dr. Holger Dressel, MPH

Institute and Outpatient Clinic for Occupational, Social and Environmental Medicine Ludwig-Maximilians-University Munich, Ziemssenstr. 1

DE-80336 München (Germany), Tel. +49 895160 2449, Fax +49 8951603957

E-Mail holger.dressel@med.uni-muenchen.de 


\section{Introduction}

Exhaled breath condensate (EBC) contains numerous biomarkers that have the potential to play a role in the diagnosis and monitoring of disease progression in respiratory disorders or in the evaluation of therapeutic interventions $[1,2]$. EBC collection has the advantage of being completely noninvasive and easily repeatable. However, in contrast to the fraction of exhaled nitric oxide $\left(\mathrm{FE}_{\mathrm{NO}}\right)$, which is increasingly used in clinical practice $[3,4]$ for asthma monitoring, a joint American Thoracic Society (ATS)/European Respiratory Society (ERS) task force concluded in 2005 that none of the biomarkers in EBC would be ready for clinical use [1]. Many methodological questions are still under debate. A major challenge is the high dilution of substances in water, with concentrations near detection limits, resulting in high variability [5]. One of the drawbacks of most specific EBC markers of inflammation or oxidative stress is the need for timeconsuming and technically demanding measurements before the results can be used in clinical decision making, compared to the immediately available information from $\mathrm{FE}_{\mathrm{NO}}$.

EBC also contains markers that can be more quickly and easily assessed, e.g. conductivity or $\mathrm{pH}$. These global measures may still contain valuable information for the assessment of respiratory conditions. However, due to their less specific nature, they may be more strongly correlated with each other and depend on each other.

The electrical conductivity of EBC fulfils the requirements of an easy- and quick-to-measure nonspecific quantity. Moreover, commercially available miniature glass measuring cells can provide conductivity data within seconds from a sampling volume of only $50-100 \mu$ l. So far, electrical conductivity in EBC has mainly been assessed to estimate the dilution of nonvolatile hydrophilic mediators [6]. EBC conductivity has been investigated less often concerning possible information for the diagnosis and monitoring of respiratory diseases.

As electrical conductivity quantifies ion content it might be related to $\mathrm{pH}$, one of the most extensively studied nonspecific markers in EBC, which has been shown to be altered in asthma [1]. In terms of practical aspects, $\mathrm{pH}$ is an interesting biomarker in $\mathrm{EBC}$ since the analysis is not very time consuming, no expensive equipment is needed, and samples can be easily stored. However, the measurement of $\mathrm{pH}$ in $\mathrm{EBC}$ might not be trivial due to the low ion concentration, difficulties in terms of reproducibility and a lack of standardization of methods, especially concerning the standardization of the carbon dioxide content [7]. Additionally, changes in $\mathrm{pH}$ are not specific to asthma and have been described in other conditions, e.g. cystic fibrosis (CF) [8].

Ammonia may be responsible for a great part of the electrical conductivity of EBC [5] and seems to be associated with $\mathrm{pH}$ [9]. Nitrite and nitrate are other nonspecific ionic biomarkers that might be associated with electrical conductivity and respiratory diseases [10] as well as with $\mathrm{FE}_{\mathrm{NO}}$ [11]. Electrical conductivity and ammonia are supposed to be markedly influenced by oral contamination [5], and EBC analyses are often performed only after lyophilization. However, this procedure again prolongs and complicates the analysis of EBC biomarkers. With regard to practical aspects and for rapid diagnosis, only the measurements of raw EBC samples seem realistic. Since the nonspecific exhaled biomarkers might be related to each other, the question of which of these markers confers independent information arises.

Based on these considerations, the aim of our study was to evaluate the correlation pattern between electrical conductivity and $\mathrm{pH}$ (measured with 2 different protocols) and ammonia and nitrite/nitrate in EBC as well as $\mathrm{FE}_{\mathrm{NO}}$ across a range of respiratory diseases. For this purpose we used factor analysis, thereby revealing the independent information.

\section{Materials and Methods}

\section{Study Subjects and Design}

The study was performed in cooperation with the pneumology departments of Ludwig-Maximilians-University in Munich. Adult patients with an established diagnosis of CF $(n=46)$ were recruited from the CF outpatient clinic. They were assessed during routine visits and none of them suffered from an exacerbation at the time of study. Nine CF patients were currently on steroid medication. Similarly, patients with chronic obstructive pulmonary disease $(C O P D ; n=17)$ and mild asthma $(n=18)$ which had been diagnosed according to standard clinical criteria were recruited from the pneumology outpatient clinic. None of them suffered from an exacerbation at the time of study. In 5 of the 18 asthmatics a regular inhalative steroid medication was documented. Lung transplant (LTX) recipients $(\mathrm{n}=14)$ without signs of acute or chronic allograft rejection were recruited from a specialized outpatient clinic for LTX patients during routine control visits.

Moreover, healthy controls $(n=26)$ in whom the absence of respiratory or other relevant disorders was assessed based on their clinical history were recruited. In an outpatient clinic setting all study participants underwent $\mathrm{FE}_{\mathrm{NO}}$ measurement followed by spirometry. Subsequently, EBC was sampled. The study was approved by the local Ethics Committee. 


\section{Exhaled Breath Condensate Measurements}

EBC was collected during 10 min of tidal breathing (ECoScreen; Viasys, Höchberg, Germany) at a collecting temperature below $-10^{\circ} \mathrm{C}$ while patients were wearing a nose clip. We did not use the aluminum collectors provided by the manufacturer but used custom-made plastic sampling tubes instead. These tubes were made from polypropylene 50 - $\mathrm{ml}$ centrifuge tubes and large pipette tips that are normally used in cell biological work. These had been additionally cleaned with distilled water and isopropanol prior to use, and measurements of conductivity had shown that no additional contribution arose from these tubes. A fraction of the sample was stored at $-32^{\circ} \mathrm{C}$ for performing the assay for nitrate and nitrite.

\section{Electrical Conductivity}

Electrical conductivity was analyzed immediately after sampling using a miniature glass measuring cell (LDM/S; WTW, Weilheim, Germany) at a temperature of $25^{\circ} \mathrm{C}$. After cleaning the measuring cell with distilled water, a fraction of the sample (20$30 \mu \mathrm{l}$ ) was aspirated to remove the water and was subsequently discarded. Then, a new portion of the sample was aspirated for the measurement.

\section{Ammonia}

Ammonia was determined by the classic Berthelot reaction involving phenol, sodium hypochlorite, and sodium pentacyanonitrosylferrat (III). In 50- $\mu$ l samples of EBC the amount of $\mathrm{NH}_{4}{ }^{+}$ions was analyzed photometrically at $620 \mathrm{~nm}$ (UV-1602; Shimadzu, Duisburg, Germany) after incubation (pH 11.8-12.4, $50^{\circ} \mathrm{C}, 1 \mathrm{~h}$ ). Four standards and 1 blank value treated in the same way as the samples were used to derive the final concentrations. The detection limit was $5 \mathrm{ng} \mathrm{NH}_{4}{ }^{+}$in $50 \mu \mathrm{l}$ and the standard deviation of repeated measurements about $2.5 \%$.

\section{pH Value}

$\mathrm{pH}$ was determined using a $\mathrm{pH}$ electrode (InLab ${ }^{\mathrm{TM}}$ Micro; Mettler-Toledo, Giessen, Germany) after equilibration with argon (Argon 5.0; Linde, Wiesbaden, Germany) for at least 30 min until a plateau was reached. This was followed by a second $\mathrm{pH}$ measurement after gassing with $2.5 \% \mathrm{CO}_{2}$ in argon (Argomag K; Linde) after equilibration for at least $30 \mathrm{~min}$ until a plateau was reached.

\section{Nitrite/Nitrate}

Nitrite and nitrate were analyzed using a chemiluminescence analyzer (NOA 280; Sievers, Boulder, Colo., USA) according to the manufacturer's instructions. Five microliters of EBC were injected with a Hamilton syringe into a purge vessel attached to the device. Nitrite and nitrate were converted to nitric oxide (NO) using a saturated solution of $\mathrm{VCl}_{3}$ in $0.8 \mathrm{M} \mathrm{HCl}$. Nitrite alone was converted to $\mathrm{NO}$ using a $1 \% \mathrm{w} / \mathrm{v}$ solution of $\mathrm{KI}$ in acetic acid. Zero values were measured using $\mathrm{N}_{2}$ gas. Final concentrations given as $\mu \mathrm{M}$ were calculated using appropriate nitrite and nitrate standards. Nitrate levels were derived by subtracting nitrite levels from the combined nitrite/nitrate levels.

\section{$F E_{N O}$ Measurement}

$\mathrm{FE}_{\mathrm{NO}}$ was determined during a single exhalation using a NOA 280 according to international guidelines [3]. After inhaling ambient air, subjects expired through a mouthpiece against a positive pressure aiming to achieve a flow rate of $50 \mathrm{ml} / \mathrm{s}$ under visual con- trol on a computer screen. Ambient air levels normally showed NO levels $<15 \mathrm{ppb}$ and a correlation analysis showed no relationship between $\mathrm{FE}_{\mathrm{NO}}$ and ambient air NO. Measurements were performed at least in triplicate. The mean of 3 reproducible values was taken for analysis. Acceptable measurements had to show a clearly identifiable plateau (within $10 \%$ of each other, typically $<5 \%$ ) and a flow rate within $10 \%$ (typically $<5 \%$ ) of the target rate during the plateau measurement. The analyzer was calibrated regularly using a certified calibration gas (Linde AG, Munich, Germany).

\section{Spirometry}

Forced vital capacity (FVC) and forced expiratory volume in $1 \mathrm{~s}\left(\mathrm{FEV}_{1}\right)$ were determined (MasterLab ${ }^{\mathrm{TM}}$; Jaeger, Würzburg, Germany) following established guidelines, and FVC \%pred, $\mathrm{FEV}_{1} \%$ pred, and $\mathrm{FEV}_{1} / \mathrm{FVC}$ were recorded [12]. At least 3 technical acceptable flow-volume maneuvers were performed and the highest values were taken.

\section{Analysis}

Results are presented as proportions or as mean values and standard deviations (SD). Values of nitrate/nitrite, nitrite, and $\mathrm{FE}_{\mathrm{NO}}$ were $\log _{10}$-transformed to achieve a normal distribution. Correspondingly, geometric mean values and standard deviations (expressed as factors with regard to the mean value and indicated by the symbol $\div$ ) are presented. Differences between groups were assessed using a $\chi^{2}$ test and analysis of variance (ANOVA). For post hoc analyses Bonferroni tests were used if variances were homogeneous; otherwise, Tamhane T2 tests were performed. $\mathrm{p}<0.05$ was considered statistically significant.

Factor analysis is a standard multivariate statistical procedure which aims to condense information contained in larger sets of variables. In essence, the procedure uses the information regarding which variables are correlated with each other. From this pattern of correlations a set of underlying factors is derived by requiring that correlated variables represent 1 factor and uncorrelated variables belong to different factors. In general, this results in a reduction of the dimensionality of the data set. In the common approach of principal component analysis (see below) the factors represent the directions in the data space in which most of the variation of the data is located. To achieve the reduction in dimensionality, a cutoff value for variation is used. Below this cutoff value all further variation is considered noise. For this purpose the so-called eigenvalues are applied (see technical description below). Ideally, factor analysis identifies a few independent factors, each of which explains the correlations between a group of variables. Correspondingly, the underlying factors are mutually independent linear combinations of variables.

In the present study the variables were different markers of exhaled breath, and factor analysis was used to reveal independent statistical factors that explained the pattern of correlations between these markers. These factors, fewer in number than the markers, would then indicate statistically independent pathophysiological features and mechanisms. It is important to note that the approach of factor analysis has already been used in various areas of respiratory research $[13,14]$.

Prior to the factor analysis Pearson correlation coefficients (r) were calculated and all statistically significant coefficients $>0.8$ are reported in the text. In technical terms, correlation coefficients were further analyzed by principal component factor analysis fol- 
Table 1. Basic characteristics, lung function, and exhaled biomarkers in the study groups

\begin{tabular}{|c|c|c|c|c|c|c|}
\hline & Controls $(n=26)$ & Asthma $(\mathrm{n}=18)$ & $\operatorname{COPD}(n=17)$ & $\mathrm{CF}(\mathrm{n}=46)$ & $\operatorname{LTX}(\mathrm{n}=14)$ & $\mathrm{p}$ \\
\hline Females & $16(61.5 \%)$ & $9(50.0 \%)$ & $10(58.8 \%)$ & $20(43.5 \%)$ & $5(35.7 \%)$ & 0.429 \\
\hline Age, years & $31.2 \pm 8.3$ & $48.3 \pm 10.9$ & $65.1 \pm 8.2$ & $32.6 \pm 7.1$ & $54.4 \pm 7.5$ & $<0.001$ \\
\hline Height, $\mathrm{cm}$ & $174 \pm 7$ & $172 \pm 10$ & $169 \pm 11$ & $172 \pm 10$ & $173 \pm 11$ & 0.653 \\
\hline Weight, kg & $67.5 \pm 12.2$ & $74.7 \pm 17.2$ & $80.2 \pm 18.0$ & $61.5 \pm 11.1$ & $72.9 \pm 12.8$ & $<0.001$ \\
\hline $\mathrm{FEV}_{1} \%$ pred & $107.2 \pm 13.0$ & $96.9 \pm 17.2$ & $53.8 \pm 21.9$ & $65.5 \pm 26.7$ & $69.3 \pm 17.3$ & $<0.001$ \\
\hline FVC \%pred & $113.0 \pm 12.7$ & $111.8 \pm 11.7$ & $79.5 \pm 18.1$ & $87.5 \pm 22.4$ & $82.9 \pm 23.0$ & $<0.001$ \\
\hline $\mathrm{FEV}_{1} / \mathrm{FVC}, \%$ & $81.2 \pm 6.3$ & $71.0 \pm 9.7$ & $52.9 \pm 14.8$ & $60.8 \pm 13.7$ & $70.1 \pm 13.5$ & $<0.001$ \\
\hline Conductivity, $\mu \mathrm{S} / \mathrm{cm}$ & $71.0 \pm 34.9$ & $94.8 \pm 45.0$ & $75.8 \pm 60.6$ & $61.8 \pm 37.8$ & $149.4 \pm 74.3$ & $<0.001$ \\
\hline $\mathrm{pH}$ argon & $8.0 \pm 0.7$ & $7.9 \pm 0.9$ & $7.3 \pm 1.3$ & $7.6 \pm 1.2$ & $8.3 \pm 0.1$ & 0.034 \\
\hline $\mathrm{pH} \mathrm{CO}_{2}$ & $5.8 \pm 0.3$ & $5.8 \pm 0.4$ & $5.6 \pm 0.6$ & $5.5 \pm 0.5$ & $6.1 \pm 0.3$ & 0.002 \\
\hline Ammonia, $\mu \mathrm{g} / \mathrm{ml}$ & $0.95 \pm 0.47$ & $1.48 \pm 0.77$ & $1.02 \pm 0.88$ & $0.98 \pm 0.62$ & $2.14 \pm 1.00$ & $<0.001$ \\
\hline Nitrite/nitrate, $\mu \mathrm{M}^{\mathrm{a}}$ & $3.73 \div 1.54$ & $3.60 \div 1.77$ & $9.48 \div 2.85$ & $6.52 \div 2.27$ & $5.78 \div 1.53$ & $<0.001$ \\
\hline Nitrite, $\mu \mathrm{M}^{\mathrm{a}}$ & $3.06 \div 1.85$ & $2.62 \div 1.90$ & $7.18 \div 3.36$ & $5.33 \div 2.31$ & $4.28 \div 1.57$ & $<0.001$ \\
\hline $\mathrm{FE}_{\mathrm{NO}}, \mathrm{ppb}^{\mathrm{a}}$ & $20.7 \div 1.9$ & $43.4 \div 2.6$ & $23.2 \div 2.2$ & $12.9 \div 2.3$ & $25.3 \div 1.4$ & $<0.001$ \\
\hline
\end{tabular}

Data are presented either as the number of subjects or as means \pm SD. $p$ values are from a $\chi^{2}$ test or ANOVA.

${ }^{\text {a }}$ Owing to data distribution the geometric mean and SD are given. SD is expressed as a factor and indicated by $\div$. The geometric mean has to be multiplied and divided by this SD factor.

lowed by rotation according to the standard varimax criterion. As outlined above, the correlation between variables is attributed to their common dependence on independent hypothetical entities termed factors. The correlation coefficients between the variables and the factors are called factor loadings. Ideally, each variable has a high loading on 1 factor, while its loadings on all the other factors are low. The number of factors necessary is determined to be as small as possible, but large enough to account for most of the information within the data; it is usually taken from the number of eigenvalues of the correlation matrix with a magnitude $>1$. The rotated component matrixes of the principal components are displayed. Finally, selected scatter plots of factor scores and single biomarkers are shown. Statistical calculations were performed using SPSS 14.0 (SPSS, Inc., Chicago, Ill., USA).

\section{Results}

Table 1 shows the basic characteristics, lung function measurements, and exhaled biomarkers in the study groups. The distributions of gender and height were comparable, whereas age and weight differed significantly between groups (ANOVA, $\mathrm{p}<0.001$ each). FEV 1 \%pred and FVC \%pred were higher in healthy subjects and patients with asthma compared to the other groups $(\mathrm{p}<0.05$ each, post hoc). In healthy subjects $\mathrm{FEV}_{1} / \mathrm{FVC}$ was higher compared to asthma, COPD, and CF patients, and the ratio was additionally higher in asthma than in COPD and CF. $\mathrm{FEV}_{1} / \mathrm{FVC}$ was also higher in LTX than in COPD patients $(\mathrm{p}<0.05$ each).
Levels of several biomarkers were elevated in LTX patients compared to other groups. Conductivity was higher compared to healthy subjects and CF patients. Furthermore, $\mathrm{pH} \mathrm{CO}_{2}$ and ammonia were higher in LTX patients than in healthy subjects, COPD patients, and CF patients. Additionally, $\mathrm{pH}$ argon was higher in LTX patients than in COPD and CF patients ( $\mathrm{p}<0.05$ each).

Nitrite/nitrate values were higher in LTX, COPD, and CF patients than in healthy subjects. Nitrite/nitrate was additionally lower in asthma than in COPD and CF. Nitrite was lower in asthmatics and controls than in CF patients ( $p<0.05$ each). Finally, $\mathrm{FE}_{\mathrm{NO}}$ was higher in asthma and LTX patients than in CF patients ( $\mathrm{p}<0.05$ each).

Figure 1 displays selected correlations between exhaled breath markers. Conductivity and ammonia showed a high linear correlation (fig. $1 \mathrm{a} ; \mathrm{r}=0.968, \mathrm{p}<0.001$ ). Correlation with conductivity was higher for $\mathrm{pH} \mathrm{CO}_{2}$ (fig. 1b; $\mathrm{r}=0.813, \mathrm{p}<0.001)$ than for $\mathrm{pH}$ argon $(\mathrm{r}=0.511, \mathrm{p}<$ 0.001). For the respective relationships with ammonia correlation coefficients were 0.810 and 0.539 ( $\mathrm{p}<0.001$ each). Correlations were also close between $\mathrm{pH}$ argon and $\mathrm{pH} \mathrm{CO}_{2}$ (fig. 1c; $\mathrm{r}=0.836, \mathrm{p}<0.001$ ) and between log nitrate/nitrite and $\log$ nitrite (fig. $1 d ; r=0.891, p<0.001$ ).

In the factor analysis concerning the exhaled biomarkers, 3 factors with eigenvalues $>1$ explaining $89 \%$ of the total variance were extracted. Conductivity, ammonia, $\mathrm{pH}$ argon, and $\mathrm{pH} \mathrm{CO}_{2}$ loaded predominantly on 1 common factor. log nitrate/nitrite and log nitrite loaded 

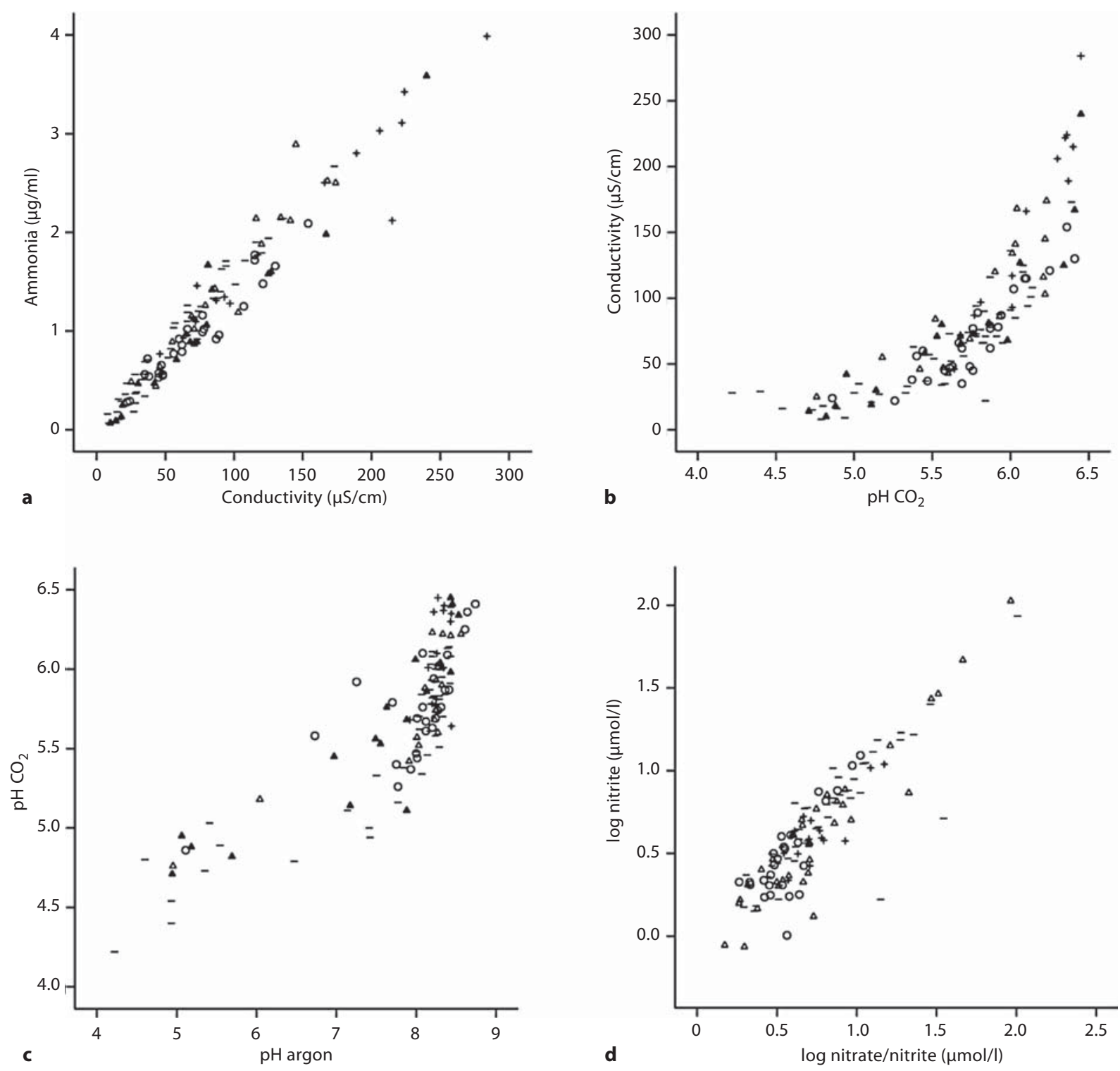

Fig. 1. Selected correlations between exhaled breath markers. In a large sample of patients with a variety of respiratory diseases as well as healthy controls, conductivity correlated generally very closely with ammonia $(\mathbf{a})(\mathrm{r}=0.968, \mathrm{p}<0.001)$ and was also clearly related to $\mathrm{pH} \mathrm{CO}_{2}(\mathbf{b})(\mathrm{r}=0.813, \mathrm{p}<0.001)$. Correlations were also generally close between $\mathrm{pH}$ argon and $\mathrm{pH} \mathrm{CO}_{2}(\mathbf{c})(\mathrm{r}=0.836$, $\mathrm{p}<0.001)$ and between $\log$ nitrate/nitrite and log nitrite $(\mathbf{d})(\mathrm{r}=$ $0.891, \mathrm{p}<0.001)$. Circles indicate healthy subjects, open triangles patients with asthma, closed triangles patients with COPD, lines patients with CF, and crosses patients after LTX. largely on a second factor. Finally, $\log \mathrm{FE}_{\mathrm{NO}}$ loaded mainly on a third factor (table 2).

Figure 2 shows scatter plots of the factor scores for factor 1 versus factor 2 and representative exhaled biomarkers, i.e. conductivity and log nitrate/nitrite, for the differ- ent study groups. Factor score 1 and thus conductivity are especially high in a subgroup of patients after LTX. Factor 2 and, correspondingly, log nitrate/nitrite show a tendency toward higher values in several COPD patients. Figure 3 displays scatter plots of factor score 3 versus factor score 2 


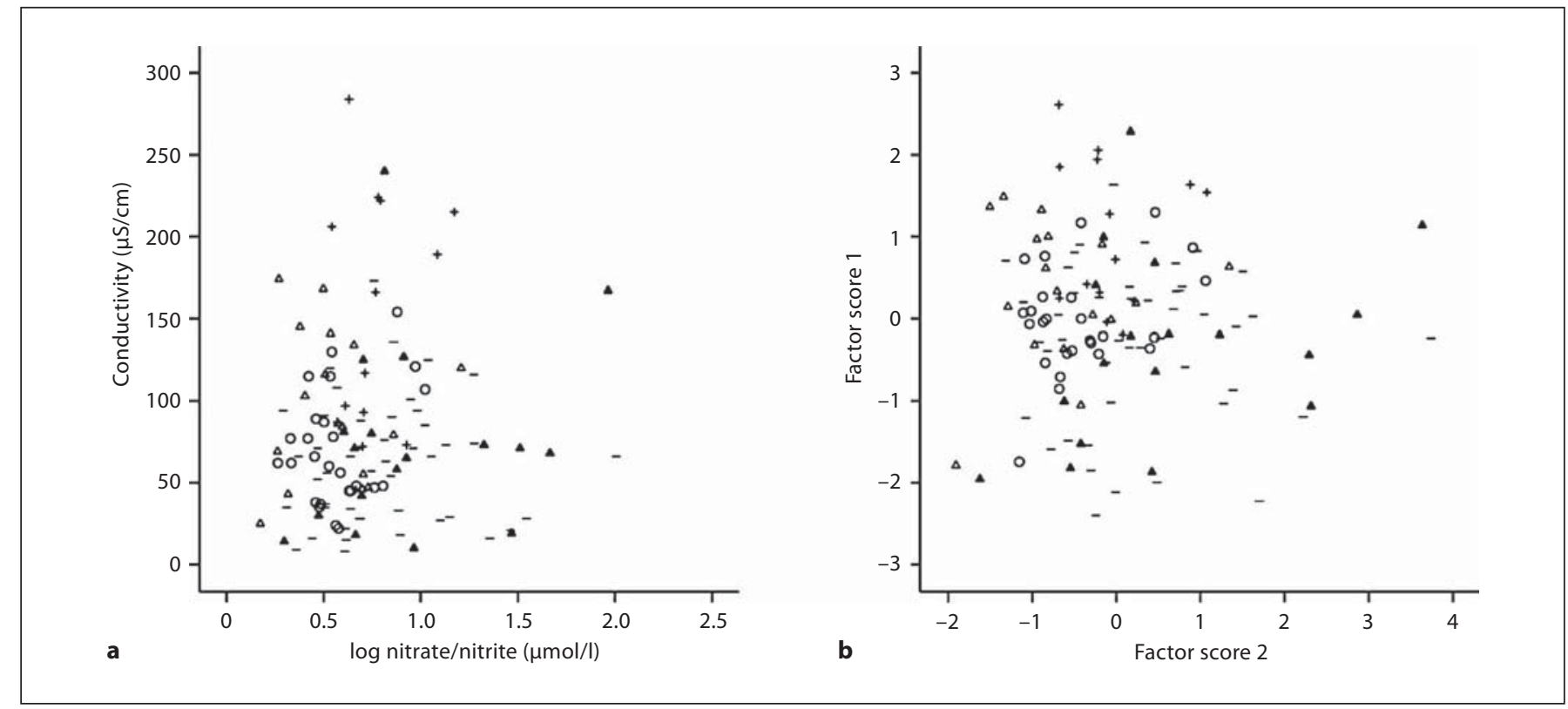

Fig. 2. a Scatter plot for conductivity versus log nitrate/nitrite. b As conductivity, ammonia, $\mathrm{pH}$ argon, and $\mathrm{pH} \mathrm{CO}_{2}$ loaded primarily on factor 1 and nitrite and nitrate/nitrite loaded primarily on factor 2 , the scatter plot for factor score 1 versus factor score 2 is shown for comparison. Factor score 1 and thus conductivity are especially high in a subgroup of patients after LTX. Factor 2 and, correspondingly, log nitrate/nitrite show a tendency toward higher values in several COPD patients. Circles indicate healthy subjects, open triangles patients with asthma, closed triangles patients with COPD, lines patients with $\mathrm{CF}$, and crosses patients after LTX.

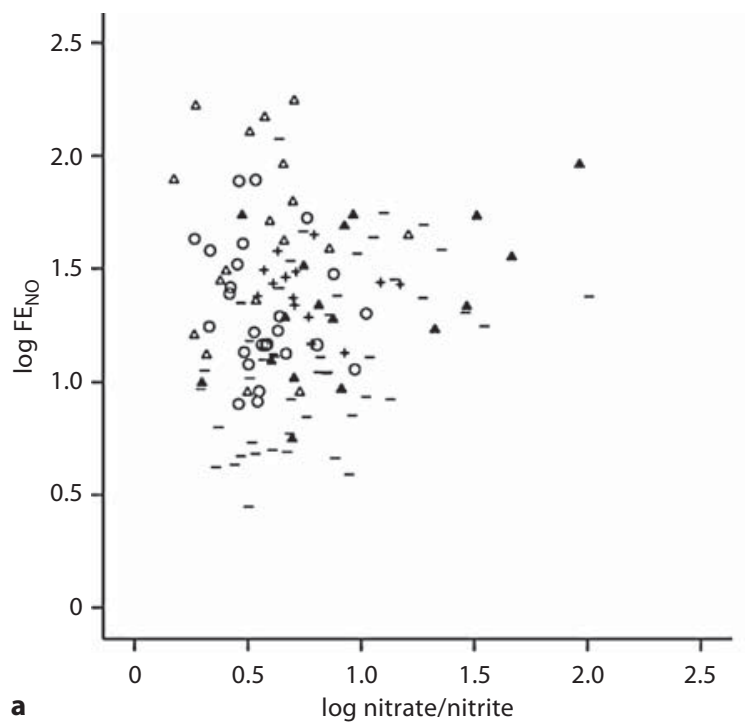

Fig. 3. a Scatter plot for $\log \mathrm{FE}_{\mathrm{NO}}$ versus $\log$ nitrate/nitrite. b As $\mathrm{FE}_{\mathrm{NO}}$ loaded primarily on factor 3 and nitrite and nitrate/nitrite loaded primarily on factor 2 , the scatter plot for factor score 3 versus factor score 2 is shown for comparison. Factor score 3 and $\log$

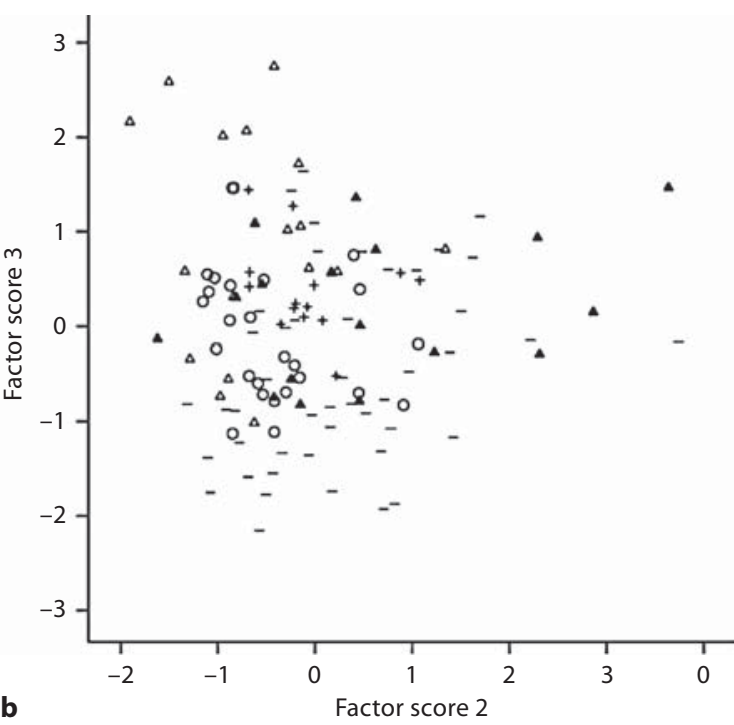

$\mathrm{FE}_{\mathrm{NO}}$ have a tendency toward high values in asthma and low values in CF. Circles indicate healthy subjects, open triangles patients with asthma, closed triangles patients with COPD, lines patients with CF, and crosses patients after LTX. 
Table 2. Rotated component matrix of the 3 principal components (factors) for all study participants $(n=121)$

\begin{tabular}{|c|c|c|c|}
\hline & \multicolumn{3}{|l|}{ Factor } \\
\hline & 1 & 2 & 3 \\
\hline Conductivity & 0.913 & 0.029 & 0.191 \\
\hline Ammonia & 0.922 & -0.024 & 0.179 \\
\hline pH argon & 0.797 & 0.107 & -0.213 \\
\hline $\mathrm{pH} \mathrm{CO}_{2}$ & 0.961 & 0.047 & -0.047 \\
\hline log nitrate/nitrite & -0.017 & 0.967 & 0.080 \\
\hline log nitrite & 0.110 & 0.970 & 0.033 \\
\hline $\log \mathrm{FE}_{\mathrm{NO}}$ & 0.044 & 0.092 & 0.960 \\
\hline
\end{tabular}

Factor loadings are presented and they can vary between -1 and +1 . The magnitude of the factor loading quantifies the correlation between the variable and the factor.

Table 3. Rotated component matrix of the 3 principal components for asthma $(\mathrm{n}=18)$

\begin{tabular}{lrrr}
\hline & \multicolumn{2}{l}{ Factor } & \\
\cline { 2 - 4 } & \multicolumn{1}{l}{2} & \multicolumn{1}{l}{3} \\
\hline Conductivity & 0.958 & -0.005 & 0.078 \\
Ammonia & 0.940 & -0.030 & 0.152 \\
pH argon & 0.695 & 0.294 & -0.535 \\
$\mathrm{pH} \mathrm{CO}_{2}$ & 0.928 & 0.086 & -0.211 \\
$\log$ nitrate/nitrite & -0.029 & 0.951 & -0.006 \\
$\log$ nitrite & 0.112 & 0.954 & 0.069 \\
$\log \mathrm{FE}_{\mathrm{NO}}$ & 0.042 & 0.108 & 0.941 \\
\hline
\end{tabular}

Table 4. Rotated component matrix of the 3 principal components for all subjects excluding asthma $(n=103)$

\begin{tabular}{lrl}
\hline & \multicolumn{2}{l}{ Factor } \\
\cline { 2 - 3 } & 1 & 2 \\
\hline Conductivity & 0.916 & 0.096 \\
Ammonia & 0.930 & 0.043 \\
$\mathrm{pH} \mathrm{argon}$ & 0.787 & 0.047 \\
$\mathrm{pH} \mathrm{CO}$ & 0.959 & 0.041 \\
$\log$ nitrate/nitrite & -0.005 & 0.948 \\
$\log$ nitrite & 0.129 & 0.936 \\
$\log \mathrm{FE}_{\mathrm{NO}}$ & 0.030 & 0.498 \\
\hline
\end{tabular}

Nonspecific Biomarkers in EBC and, accordingly, of log $\mathrm{FE}_{\mathrm{NO}}$ and log nitrate/nitrite. Factor score 3 and $\log \mathrm{FE}_{\mathrm{NO}}$ have a tendency toward high values in asthma and low values in CF.

When including only subjects with asthma in the factor analysis $(\mathrm{n}=18)$, once again the 3 factors listed above could be clearly extracted (table 3 ). When restricting the factor analysis to subjects without asthma $(\mathrm{n}=103)$ only 2 factors were extracted, with conductivity, ammonia, $\mathrm{pH}$ argon, and $\mathrm{pH} \mathrm{CO}_{2}$ loading mainly on the first factor and $\log$ nitrate/nitrite, $\log$ nitrite, and $\log \mathrm{FE}_{\mathrm{NO}}$ loading on the second factor (table 4).

\section{Discussion}

Using factor analysis in a large sample of healthy subjects and patients with various lung diseases, we could reduce the information of a number of nonspecific exhaled breath measures to 3 distinct dimensions. The first comprised conductivity, ammonia, and $\mathrm{pH}$. The second comprised nitrite and nitrate, and the third comprised $\mathrm{FE}_{\mathrm{NO}}$.

The correlation between electrical conductivity and ammonia in our sample was near perfect, which is in line with the finding that ammonia far exceeds the concentrations of any other ion in EBC [5]. Thus, it can be assumed that electrical conductivity is a surrogate marker for ammonia content throughout diseases that is immediately available and easy to measure compared with standard ammonia detection methods. When deriving a linear regression equation $(\mathrm{r}=0.968)$ from our data $(\mathrm{n}=121)$, ammonia in $\mu \mathrm{g} / \mathrm{ml}$ was calculated as $-0.058+0.016 \times$ conductivity $(\mu \mathrm{S} / \mathrm{cm})$.

As ammonia is the largest constituent of ionic concentration, it is thought to play an important role in $\mathrm{EBC} \mathrm{pH}$ [5]. In our samples the association between conductivity, ammonia, and $\mathrm{pH}$ was highest when $\mathrm{pH}$ was standardized for $\mathrm{CO}_{2}$. $\mathrm{pH}$ in native $\mathrm{EBC}$ samples yielded much less stable readings. Argon deaeration is the standard procedure to remove volatile components, e.g. $\mathrm{CO}_{2}$, and to obtain stable $\mathrm{pH}$ readings [1]. However, it has been shown that $\mathrm{CO}_{2}$ is still variable in samples after argon deaeration and that $\mathrm{CO}_{2}$ is closely related with $\mathrm{pH}$. Therefore, $\mathrm{CO}_{2}$ standardization of $\mathrm{EBC}$ has been postulated as the most reproducible method for $\mathrm{pH}$ assessment [7]. $\mathrm{CO}_{2}$ standardization should represent the physiological milieu better than deaeration by argon. Under these more physiological conditions an association that is hidden when using other methods might be revealed.

Nitrite and the ratio nitrite/nitrate represented a second distinct dimension and $\mathrm{FE}_{\mathrm{NO}}$ a third when considering 
our whole study population or the subgroup with asthma. However, when analyzing only subjects without asthma, $\mathrm{FE}_{\mathrm{NO}}$ could be attributed to a common factor together with the nitrogen oxides. Thus $\mathrm{FE}_{\mathrm{NO}}$ seems to contain independent information mainly in asthma, as expected. Similarly, $\mathrm{FE}_{\mathrm{NO}}$ has been found not to be significantly correlated with EBC nitrite/nitrate in a study in asthmatic children [11]. In general, changes in nitrogen oxide concentrations are known not only to reflect NO formation, but also to depend on a variety of other physiological or pathophysiological conditions in the airways [15].

A novel finding of our study was the elevated conductivity in lung transplant recipients in parallel to increased ammonia and $\mathrm{pH} \mathrm{CO}_{2}$. To our knowledge conductivity has been used to assess the dilution of EBC samples [6] but not as a potential disease marker. Severe hyperammonaemia is a rare complication after lung transplantation [16] and in this condition ammonia may also be elevated in EBC. The patients included in our study did not suffer from this complication; however, affections of the liver and kidneys may have contributed to the increased ammonia content in EBC. Nephrotoxicity and renal failure are typical complications of the medication after LTX. As electrical conductivity and ammonia are supposed to be markedly influenced by oral contamination [5], changes in the microbiological flora of the mouth after lung transplantation may play an additional role. Ammonia has also been described as being associated with $\mathrm{pH}$ [9]. We found an elevated $\mathrm{pH} \mathrm{CO} \mathrm{CO}_{2}$ in LTX patients. In LTX airway acidification has been described in bronchiolitis obliterans syndrome and in acute allograft rejection [17]. However, another study measuring $\mathrm{pH}$ at a standard $\mathrm{CO}_{2}$ partial pressure found no difference between stable LTX patients and healthy volunteers [18].

There were no further significant changes concerning conductivity, ammonia, and $\mathrm{pH}$ in the other diseases under study compared to healthy controls.

We found elevated nitrite/nitrate levels in COPD and CF patients as well as in LTX recipients compared to healthy subjects, but not in asthmatics. This may be due to the fact that we only examined patients with mild asthma. Our data are in line with another study which found normal nitrite levels in patients with mild asthma in contrast to elevated values in patients with severe asthma [19]. In the ATS/ERS statement concerning EBC [1], nitrite and nitrite/nitrate were described as elevated in asthma, CF, and bronchiectasis and this was attributed to an increased NO metabolism. However, similar to ammonia, the source of nitrite/nitrate is under debate [15]. It has recently been demonstrated that nitrite in EBC orig- inates to a large extent in the pharyngo-oral tract as a product of nitrate-reducing bacteria [20]. NO can be formed in the pharyngo-oral tract through the reduction of salivary nitrite and thus contributes to the level of NO in exhaled breath [21].

The influences of disease severity as well as treatment effects on single exhaled biomarkers have been described $[4,22,23]$. Our study was not designed to contribute to these findings as its scope was the correlation between the different biomarkers across a broad range of patients with respiratory diseases as well as healthy subjects. Concerning the exhaled biomarkers no differences could be detected with regard to asthma, COPD severity, or steroid use in asthma or CF in our sample. The only association between a biomarker under study and a parameter of disease severity was suggested by a weak correlation between $\mathrm{Fe}_{\mathrm{NO}}$ and $\mathrm{FEV}_{1}$ \%pred in CF patients $(\mathrm{r}=0.276, \mathrm{p}=0.002)$. This is in line with other data [23]. As stated above, due to the inhomogeneous study population and low case numbers in subgroups, no conclusions concerning the clinical value of single biomarkers to assess disease severity or treatment effects can be drawn. However, the heterogeneity of the study population was a prerequisite to study the overall correlation of the biomarkers.

In conclusion, our data suggested that the information contained in a number of nonspecific exhaled breath markers that were assessed in a variety of respiratory conditions and in healthy subjects could be reduced to 3 independent factors. The information content of conductivity, ammonia, and $\mathrm{pH} \mathrm{CO}_{2}$ seemed to be comparable in untreated $\mathrm{EBC}$. $\mathrm{FE}_{\mathrm{NO}}$ was found to be an independent dimension mainly in asthma, but was associated with nitrite/nitrate when considering the study population excluding asthma. Thus our study suggests there are only 2 or 3 statistically independent factors derived from a broader panel of biomarkers. This finding may have implications for research with and clinical use of EBC markers as the number of biomarkers assessed may be reduced in future studies without a significant loss of information. There was a considerable overlap in the ranges of biomarkers between study subgroups. However, patients with LTX showed different values as indicated by increased conductivity, $\mathrm{pH} \mathrm{CO}$, ammonia, and nitrite/nitrate, suggesting a potential role in the monitoring of LTX.

\section{Acknowledgements}

We thank A. Kronseder for providing technical support in method validation and $\mathrm{D}$. de la Motte for providing support in performing and organizing measurements. 


\section{References}

-1 Horvath I, Hunt J, Barnes PJ, Alving K, Antczak A, Baraldi E, et al: Exhaled breath condensate: methodological recommendations and unresolved questions. Eur Respir J 2005; 26:523-548.

2 Kharitonov SA, Barnes PJ: Exhaled biomarkers. Chest 2006;130:1541-1546.

$\checkmark 3$ American Thoracic Society, European Respiratory Society: ATS/ERS recommendations for standardized procedures for the online and offline measurement of exhaled lower respiratory nitric oxide and nasal nitric oxide, 2005. Am J Respir Crit Care Med 2005; 171:912-930.

$\checkmark 4$ Taylor DR, Pijnenburg MW, Smith AD, De Jongste JC: Exhaled nitric oxide measurements: clinical application and interpretation. Thorax 2006;61:817-827.

$\checkmark 5$ Effros RM, Dunning MB 3rd, Biller J, Shaker $\mathrm{R}$ : The promise and perils of exhaled breath condensates. Am J Physiol Lung Cell Mol Physiol 2004;287:L1073-L1080.

6 Effros RM, Biller J, Foss B, Hoagland K, Dunning $\mathrm{MB}$, Castillo $\mathrm{D}$, et al: A simple method for estimating respiratory solute dilution in exhaled breath condensates. Am J Respir Crit Care Med 2003;168:1500-1505.

$\checkmark 7$ Kullmann T, Barta I, Lazar Z, Szili B, Barat E, Valyon M, et al: Exhaled breath condensate $\mathrm{pH}$ standardised for $\mathrm{CO}_{2}$ partial pressure. Eur Respir J 2007;29:496-501.

-8 Ojoo JC, Mulrennan SA, Kastelik JA, Morice $\mathrm{AH}$, Redington AE: Exhaled breath condensate $\mathrm{pH}$ and exhaled nitric oxide in allergic asthma and in cystic fibrosis. Thorax 2005; 60:22-26.
-9 Carraro S, Folesani G, Corradi M, Zanconato S, Gaston B, Baraldi E: Acid-base equilibrium in exhaled breath condensate of allergic asthmatic children. Allergy 2005;60: 476-481.

10 Corradi M, Pesci A, Casana R, Alinovi R, Goldoni M, Vettori MV, et al: Nitrate in exhaled breath condensate of patients with different airway diseases. Nitric Oxide 2003;8: 26-30.

11 Ratnawati, Morton J, Henry RL, Thomas PS: Exhaled breath condensate nitrite/nitrate and $\mathrm{pH}$ in relation to pediatric asthma control and exhaled nitric oxide. Pediatr Pulmonol 2006;41:929-936.

12 American Thoracic Society: ATS/ERS standardization of lung function testing: standardization of spirometry. Am J Respir Crit Care Med 2005;26:319-338.

13 Riekert KA, Eakin M: Factor analysis: a primer for asthma researchers. J Allergy Clin Immunol 2008;121:1181-1183.

14 Wegner RE, Jörres RA, Kirsten DK, Magnussen $\mathrm{H}$ : Factor analysis of exercise capacity, dyspnoea ratings and lung function in patients with severe COPD. Eur Respir J 1994; 7:725-729.

15 Silkoff PE, Erzurum SC, Lundberg JO, George SC, Marczin N, Hunt JF, et al: ATS workshop proceedings: exhaled nitric oxide and nitric oxide oxidative metabolism in exhaled breath condensate. Proc Am Thorac Soc 2006;3:131-145.
16 Kotloff RM, Ahya VN: Medical complications of lung transplantation. Eur Respir J 2004;23:334-342.

17 Dupont LJ, Dewandeleer Y, Vanaudenaerde BM, Van Raemdonck DE, Verleden GM: The $\mathrm{pH}$ of exhaled breath condensate of patients with allograft rejection after lung transplantation. Am J Transplant 2006;6:1486-1492.

18 Czebe K, Kullmann T, Csiszer E, Barat E, Horvath I, Antus B: Variability of exhaled breath condensate $\mathrm{pH}$ in lung transplant recipients. Respiration 2008;75:322-327.

19 Corradi M, Montuschi P, Donnelly LE, Pesci A, Kharitonov SA, Barnes PJ: Increased nitrosothiols in exhaled breath condensate in inflammatory airway diseases. Am J Respir Crit Care Med 2001; 163:854-858.

20 Marteus H, Tornberg DC, Weitzberg E, Schedin U, Alving K: Origin of nitrite and nitrate in nasal and exhaled breath condensate and relation to nitric oxide formation. Thorax 2005;60:219-225.

$>21$ Zetterquist W, Pedroletti C, Lundberg JO, Alving K: Salivary contribution to exhaled nitric oxide. Eur Respir J 1999;13:327-333.

22 Liu L, Urban P, Hunt JF, Wilkinson P, Laning $\mathrm{K}$, Gaston B: Changes in exhaled nitric oxide and breath $\mathrm{pH}$ during fluticasone wean in asthma. Respiration 2010;79:193-199.

23 Keen C, Gustafsson P, Lindblad A, Wennergren G, Olin AC: Low levels of exhaled nitric oxide are associated with impaired lung function in cystic fibrosis. Pediatr Pulmonol 2010;45:241-248 